\title{
Controlling PCBM aggregation in P3HT/PCBM film by a selective solvent vapor annealing
}

\author{
SUN Yue, HAN YanChun \& LIU JianGang* \\ State Key Laboratory of Polymer Physics and Chemistry, Changchun Institute of Applied Chemistry, Chinese Academy of Sciences, \\ Changchun 130022, China
}

Received February 27, 2013; accepted May 15, 2013; published online June 27, 2013

\begin{abstract}
A selective solvent vapor, i.e., cyclohexanone or isopropyl benzene, which is a poor solvent for poly(3-hexylthiophene-2,5-diyl) (P3HT) and a good solvent for fullerene derivative [6,6]-phenyl-C61-butyric acid methyl ester (PCBM), was employed to reduce the size of PCBM aggregates and prolong the formation time of big PCBM aggregates in P3HT/PCBM film. PCBM nucleates and aggregates of 10-20 nm scale form in the first few minutes annealing. Then the size of PCBM aggregates kept unchanged until annealing for $60 \mathrm{~min}$. Finally, larger PCBM aggregates of micron-size formed hours later. On the contrary, the growth rate of PCBM aggregates was faster and their size was larger when treated with a good solvent vapor for both components. The P3HT crystallinity was the same with different types of annealing solvents, although the rate of P3HT self-organization was decreased after a selective solvent vapor annealing. Because of the smaller size of phase separation, the device annealed in a selective solvent vapor for $30 \mathrm{~min}$ had a higher PCE than that annealed in a good solvent vapor.
\end{abstract}

P3HT crystallinity, PCBM aggregation, selective solvent vapor annealing

Citation: $\quad$ Sun Y, Han Y C, Liu J G. Controlling PCBM aggregation in P3HT/PCBM film by a selective solvent vapor annealing. Chin Sci Bull, 2013, 58: 2767-2774, doi: 10.1007/s11434-013-5944-6

Recent years, polymer solar cells have attracted lots of interests due to their advantages compared with inorganic solar cells such as easy processability, light weight, low cost, flexible and so on. Regioregular poly(3-hexyl-thiophene2,5-diyl) (rr-P3HT) and fullerene derivative [6,6]-phenylC61-butyric acid methyl ester (PCBM) are respectively one of the most important donor and acceptor materials in polymer solar cells. The power conversion efficiency of devices based on them has been up to $5 \%-6 \%$ [1-3].

A great deal of research has proved that the morphology of the photoactive layer is crucial for highly efficient performance. Ideally, the donor and acceptor materials should form interpenetrated networks of 10-20 nm-scale on account of the typical exciton diffusion length which is about $10 \mathrm{~nm}$ for conjugated polymers [4,5]. When represented by a two-dimensional model, it showed that a phase separated morphology with feature sizes smaller than $\sim 50 \mathrm{~nm}$ could

*Corresponding author (email: niitawh@ciac.jl.cn) improve charge transport within and between the two phases and reduce bimolecular charge recombination [6]. In the case of P3HT/PCBM, the molecular ordering of rr-P3HT is concerned with photon absorption and hole transport [7-9], and the suitable size of phase separation is related to charge separation. In order to achieve an optimum morphology, many methods have been employed, including thermal annealing [10,11], solvent vapor annealing [12-14], mixed solvent $[15,16]$, introduction of additives $[17,18]$ and so on. Most of these methods can induce P3HT to self-organize into ordered structure. In fact, the crystallization of P3HT is always faster than the aggregation of PCBM $[19,20]$. When the crystallinity of P3HT is enhanced, crystallization-driven phase separation will happen $[21,22]$. As a result, big (even micron-sized) PCBM aggregates often appear. The scale of them was obviously much greater than the exciton diffusion length. Meanwhile, the diffusion of PCBM out of the polymer matrix to form aggregates enables the disordered P3HT to further crystallize [7], not disrupts the ordered lamellar 
stacking of P3HT chains [23]. Although ordered structure of P3HT leads to enhanced absorption and a high hole mobility, excessive phase separation results in the increasing exciton loss [24]. Therefore, simultaneously controlling the size of PCBM aggregates and increasing the crystallinity of P3HT are crucial to achieve a high PCE. Room-temperature solvent vapor annealing is a relatively mild condition compared with high-temperature thermal annealing, and the diffusion and aggregation of PCBM molecules is relatively slow during P3HT crystallization [25]. Solubility of annealing solvent has an import influence on the phase separation and the crystallinity of P3HT. However, a good solvent vapor annealing can also induce excessive phase separation [14]. Annealing by a poor solvent vapor for both P3HT and PCBM can obtain small-scale phase separation at the cost of the crystallinity of P3HT [24]. Thus, increasing the number of PCBM aggregates and delaying the rate of crystallization rates of P3HT will be efficient to obtain a proper aggregation of PCBM.

In this paper, a selective solvent vapor, cyclohexanone or isopropyl benzene, which is poor for P3HT and good for PCBM, is employed to induce PCBM to aggregate first and decrease the rate of $\mathrm{P} 3 \mathrm{HT}$ crystallization. The process and mechanisms of PCBM aggregation with enhanced annealing time is traced and discussed.

\section{Experimental}

Regioregular HT-HT P3HT (RR>98.5\%; HT: head-to-tail; $M_{\mathrm{n}}=68 \mathrm{kDa}$ ) was purchased from Sigma-Aldrich Co. Ltd. (USA) PCBM with a purity of $99 \%$ was purchased from Solenne Co. Ltd. (Netherlands) and used as received. The solvent to dissolve P3HT and PCBM, chlorobenzene (Beijing Chemical, China), was used after purification. The solvents for vapor annealing, chlorobenzene (Beijing Chemical, China), cyclohexanone (Beijing Chemical, China) and isopropyl benzene (Shanghai Yingyuan Chemical Co. Ltd., China) were used as received.

The solution used in this study for spin-coating active layer was prepared as follows: P3HT and PCBM (1:1 wt/wt) were dissolved in chlorobenezene to make total $20 \mathrm{mg} / \mathrm{mL}$ solution. This solution was stirred over night at room temperature in a glove box. The spin-coating speed was 1000 $\mathrm{r} / \mathrm{min}$ and the time was $60 \mathrm{~s}$. The solvent vapor annealing process was carried out in a glass Petri dish containing solvents covered with a glass cap at room temperature. The distance between the films and liquid level is about $35 \mathrm{~mm}$.

The morphology of P3HT films was characterized using atomic force microscopy (AFM) and transmission electron microscope (TEM). The crystal structure of P3HT was analyzed using grazing incidence X-ray diffraction (GIXD). The UV-Vis absorption spectra of blend thin films were recorded with a Lambda 750 spectrometer (Perkin-Elmer, Wellesley, MA, USA).

The photovoltaic devices were prepared on glass/ITO substrates. A 45-nm-thick poly(ethylenedioxythiophene): poly (styrenesulfonate) (PEDOT: PSS, Baytron P4083) layer was deposited by spin-coating (2500 r/min and $60 \mathrm{~s})$ and then dried at $120^{\circ} \mathrm{C}$ for $30 \mathrm{~min}$. The solution of P3HT and PCBM was spin-coated (1000 r/min, $60 \mathrm{~s})$ onto PEDOT: PSS after filtered. After drying the devices were annealed in solvent vapor as described above. Finally, 1-nm-thick LiF and 80nm-thick Al electrodes were deposited on samples by CVD, respectively. The active surface area of typical device is $0.12 \mathrm{~cm}^{2}$. Current density-voltage (JV) curves of the photovoltaic devices under white light illumination were measured using a computer-controlled Keithley 236 sourcemeter.

\section{Results and discussion}

Two types of solvent with almost the same boiling point (the solubility is listed in Table 1) were chosen. One is good for both components and the other is a selective solvent which is poor for P3HT and good for PCBM. In a selective solvent vapor, the growth rate of PCBM aggregates is much slower than that in a good solvent vapor (Table 2). In order to clarify the role played by solvent vapor in aggregation of PCBM, we investigated the morphology evolution of P3HT/ PCBM films treated with different solvent vapors. Firstly, the morphological evolution of the blend films treated by a good or a selective solvent vapor were investigated, respectively. Then, the crystallization of P3HT was studied. Thirdly,

Table 1 The solubility for P3HT and PCBM in different solvents ${ }^{\text {a) }}$

\begin{tabular}{lccc}
\hline & $\begin{array}{c}\text { Boiling point } \\
\left({ }^{\circ} \mathrm{C}\right)\end{array}$ & $\begin{array}{c}\text { Solubility for } \\
\text { P3HT }(\mathrm{mg} / \mathrm{mL})\end{array}$ & $\begin{array}{c}\text { Solubility for } \\
\text { PCBM }(\mathrm{mg} / \mathrm{mL})\end{array}$ \\
\hline Cyclohexanone & 155.6 & $<10$ & $>10$ \\
Isopropyl benzene & 152.0 & $<10$ & $>10$ \\
Chlorobenzene & 132.0 & $>>10$ & $>>10$ \\
\hline
\end{tabular}

a) The measurement was taken at room temperature.

Table 2 Mean area of PCBM domains $\left(\mathrm{nm}^{2}\right)^{\mathrm{a})}$

\begin{tabular}{lcccc}
\hline \multicolumn{1}{c}{ Time } & $1 \mathrm{~min}$ & $0.5 \mathrm{~h}$ & $1 \mathrm{~h}$ & $2 \mathrm{~h}$ \\
\hline Cyclohexanone vapor & $1.59 \times 10^{2^{*}}$ & $1.43 \times 10^{2}$ & $4.29 \times 10^{2}$ & $1.10 \times 10^{4}$ \\
Isopropyl benzene & $2.01 \times 10^{2^{*}}$ & $3.14 \times 10^{2}$ & $3.42 \times 10^{2}$ & $2.28 \times 10^{4}$ \\
Chlorobenzene vapor & - & $2.70 \times 10^{4}$ & $1.72 \times 10^{7}$ & $4.02 \times 10^{5}$ \\
$3.85 \times 10^{7}$ & $1.30 \times 10^{7}$ &
\end{tabular}

a) The data with * came from AFM phase images (because of the small size phase separation, the data of TEM images was difficult for statistics), and others came from TEM images. 
the role that solvent vapors played in P3HT/PCBM films was discussed in detail. Finally, photovoltaic devices based on P3HT/PCBM blend films annealed under different conditions were fabricated and their performances were measured.

\subsection{A good solvent vapor: PCBM aggregations grow fast with time}

One main difference of the blend film treated with different solvent vapor lies in the size of PCBM aggregates. Because PCBM $\left(1.5 \mathrm{~g} / \mathrm{cm}^{3}\right)$ has a higher density than P3HT (1.1 $\left.\mathrm{g} / \mathrm{cm}^{3}\right)$, the dark and light region in transmission electron microscopy images represented PCBM and P3HT domains, respectively. In Bright-field TEM images, the phase separation in P3HT/PCBM films grows excessively with time and there are even micro-size PCBM aggregates forming after annealed in chlorobezene vapor for $120 \mathrm{~min}$ (Figure 1). These results agree with previous reports $[10,18]$.

\subsection{A selective solvent vapor: Reducing aggregate size and prolonging formation time of big aggregates}

Figure 2 shows the TEM and AFM images of blend films annealed for different time in a selective solvent vapor, cyclohexanone or isopropyl benzene. The surface of as-spun film is covered with short nanofibers (Figure 2(a), (a)'). While a large number of spherical aggregates with 10-20 nm diameters form only after annealing for $1 \mathrm{~min}$ in cyclohexanone vapor, they are not found in the as-spun film at all (Figure 2(b)). Tang et al. [26] also found the similar structure and the spherical aggregates are attributed to PCBM. In Bright-field TEM images (Figure 2(b)'), lots of dark dots

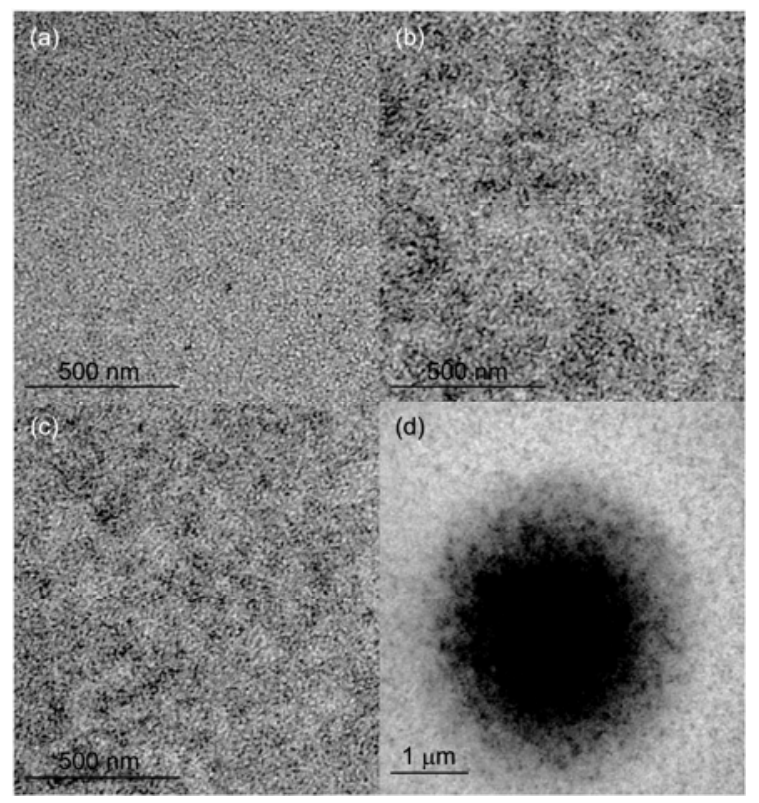

Figure 1 Transmission electron microscope images of P3HT/PCBM blend films annealed by chlorobezene vapor for different time. (a) $1 \mathrm{~min}$; (b) $30 \mathrm{~min}$; (c) $60 \mathrm{~min}$; (d) $120 \mathrm{~min}$. with $\sim 20 \mathrm{~nm}$ size appear, so we confirme that the spherical aggregates are PCBM. This structure is favorable for solar cells, because the length of exciton diffusion is about $10 \mathrm{~nm}$ and the ideal domain size is about twice of the length of exciton diffusion in theory. After annealing for $30 \mathrm{~min}$, this structure does not change any more (Figure 2(c), 2(c)'). In fact, the dimension of PCBM aggregates keep almost unchanged for about $60 \mathrm{~min}$ in cyclohexanone vapor (Figure 2(d)). However, excessive phase separation forms hours later, as shown in Figure 2(e), where PCBM aggregates with several hundreds nanometers size appear. Aside from cyclohexanone, isopropyl benzene vapor is employed, too. It is also a selective solvent similar to cyclohexaone with nearly the same boiling point. The morphological evolution of the films treated with isopropyl benzene is the same as that of films treated with cyclohexanone (Figure 2(f)-(i)). PCBM aggregates with a small size form fast and keep nearly unchanged for about $1 \mathrm{~h}$ (Figure 2(f)-(h)). Hours later PCBM aggregates of the large-size appear (Figure 2(i)).

The mean area of PCBM aggregates in films annealed in various solvent vapors for different time is listed in Table 2. The size of PCBM aggregates increases with enhanced annealing time. In cyclohexanone and isopropyl benzene vapor, the growth rate of PCBM aggregates is much slower than that in chlorobenzene vapor. In cyclohexanone vapor, the size of PCBM aggregates hasalmost the same order of magnitude when annealed for less than $1 \mathrm{~h}$. The mean area of PCBM aggregates increase from $\sim 150$ to $\sim 430 \mathrm{~nm}^{2}$ when the films are annealed for from $1 \mathrm{~min}$ to $1 \mathrm{~h}$. After annealed for $2 \mathrm{~h}$, the mean area of PCBM aggregates increases, and it is $5.53 \times 10^{5} \mathrm{~nm}^{2}$ when the films are annealed for $4 \mathrm{~h}$. When annealed in isopropyl benzene vapor, the mean area of PCBM aggregates is smaller than $\sim 350 \mathrm{~nm}^{2}$ when annealed for less than $1 \mathrm{~h}$. Then it increases with annealing time and is up to $4.02 \times 10^{5} \mathrm{~nm}^{2}$ after the films are annealed for $4 \mathrm{~h}$. However, in chlorobenzene vapor, the growth rate of PCBM aggregations is fast. The mean area of PCBM aggregations is $2.7 \times 10^{4} \mathrm{~nm}^{2}$ after annealed for only $30 \mathrm{~min}$, and up to $1.72 \times 10^{7} \mathrm{~nm}^{2}$ when annealed for $1 \mathrm{~h}$.

After annealed in a selective solvent vapor, lots of PCBM aggregates with 10-20 nm diameters will form in the P3HT/PCBM films at first, and their size is maintained for almost $60 \mathrm{~min}$. On the contrary, the phase separation in P3HT/PCBM films grows excessively with enhanced annealing time in a good solvent vapor. It indicates that a selective solvent vapor rather than a good solvent vapor is preferred to promote PCBM to nucleate greatly and aggregate with a small size. In other words, the selective solvent vapor can reduce the size of PCBM aggregates and prolong the formation of big PCBM aggregates.

\subsection{The influence of different types of annealing solvents on P3HT crystallization}

A well-ordered P3HT crystallite is also a significant factor 

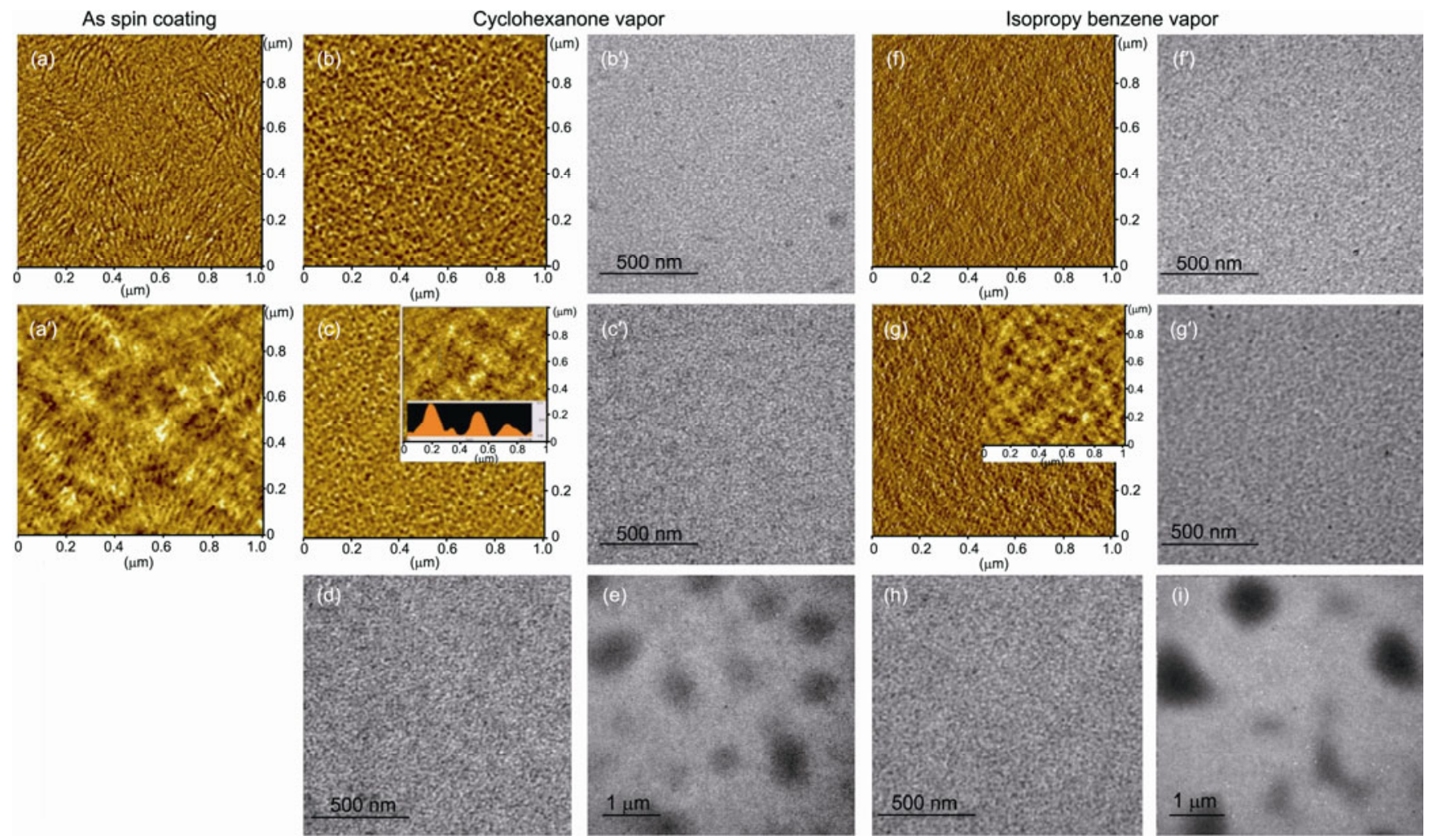

Figure 2 Transmission electron microscope and the atomic force microscope phase images of P3HT/PCBM blend films annealed in selective solvent vapor for different times: $\left.0 \min \left((\mathrm{a}),(\mathrm{a})^{\prime}\right), 1 \mathrm{~min}(\mathrm{(b}),(\mathrm{b})^{\prime},(\mathrm{f}),(\mathrm{f})^{\prime}\right), 30 \mathrm{~min}\left((\mathrm{c}),(\mathrm{c})^{\prime},(\mathrm{g}),(\mathrm{g})^{\prime}\right), 60 \mathrm{~min}((\mathrm{~d}),(\mathrm{h}))$ and $240 \mathrm{~min}((\mathrm{e}),(\mathrm{i}))$. (a') and the inset images in (c), (g) are the height images of (a), (c), (g). Among them, (b), (b)', (c), (c)', (d), (e) and (f), (f)', (g), (g)', (h), (i) are the films annealed in cyclohexanone and isopropyl benzene vapor, respectively.

for improving performance. The GIXD profiles of P3HT/ PCBM films annealed in different vapors are shown in Figure 3(a)-(c). The (100) peak is corresponding to an out-of-plane orientation of $a$-axis in which the main chain parallel and the alkyl side perpendicular to the substrate. All the annealed films showed an intense (100) diffraction peak at $2 \theta=5.5^{\circ}$, while the as-spun films at $2 \theta=5.3^{\circ}$. It indicates the distance of $a$-axis is shorter after solvent vapor annealing according to Bragg's law $(2 d \sin \theta=n \lambda)$. The height of the diffraction peak at $2 \theta=5.5^{\circ}$ or $5.3^{\circ}$ is proportional to the number of P3HT nanodomains per unit volume and, consequently, to the crystallinity of the investigated samples when the films have the same area and thickness. In order to discuss the effect of solvent on the crystallization of P3HT, the intensity evolution of the (100) peak with annealing time in cyclohexanone and chlorobenzene vapor is showed in Figure 3(d). Interestingly, the intensity of the (100) peak is almost the same after annealing for some time in both a selective and a good solvent vapor. It means that a selective solvent vapor can also effectively induce P3HT chains from disordered to well-ordered and does not limit the photon absorption and hole transport after annealed for $30 \mathrm{~min}$ or longer. However, the crystallization rates of P3HT are different when annealed for the first few minutes. The intensity of the (100) peak in films after annealed in cyclohexanone vapor for $1 \mathrm{~min}$ is weaker than that in chlorobenzene vapor for $1 \mathrm{~min}$. It is concluded that the crystallinity of P3HT has nothing to do with the types of annealing solvents, although the rate of P3HT crystallization in cyclohexanone vapor is slower than that in chlorobenzene vapor.

The UV-Vis absorption spectra also prove this conclusion. There are few differences between the films annealed in cyclohexanone vapor and in isopropyl benzene vapor. Thus, we only compare the films annealed in cyclohexanone vapor and in chlorobenzene vapor here. The UV-visible absorption spectra clearly show two peaks: one at 332 $\mathrm{nm}$ corresponds to PCBM and the other peak between 490 $\mathrm{nm}$ and $607 \mathrm{~nm}$ representing the P3HT (Figure 4). In UV-Vis absorption spectra, all the films annealed in solvent vapor have a red shift of max absorption from 490 to 515 $\mathrm{nm}$ and two vibronic absorption shoulders at 558 and 607 $\mathrm{nm}$, which are distinct from the as-spun film. The max absorption peak is the absorption of P3HT main chain. The peak at $558 \mathrm{~nm}$ is attributed to the absorption of extended conjugation lengths in the solid state and the peak at $607 \mathrm{~nm}$ comes from the interchain transition of P3HT. The intensity of the peak at $607 \mathrm{~nm}$ gradually increases with enhanced annealing time in cyclohexanone vapor (Figure 4(a)). However, when annealed in chlorobenzene vapor, it increases quickly in the beginning and then keeps almost the same intensity later (Figure 4(b)). It means a good solvent vapor is more prone to induce self-organization of P3HT 

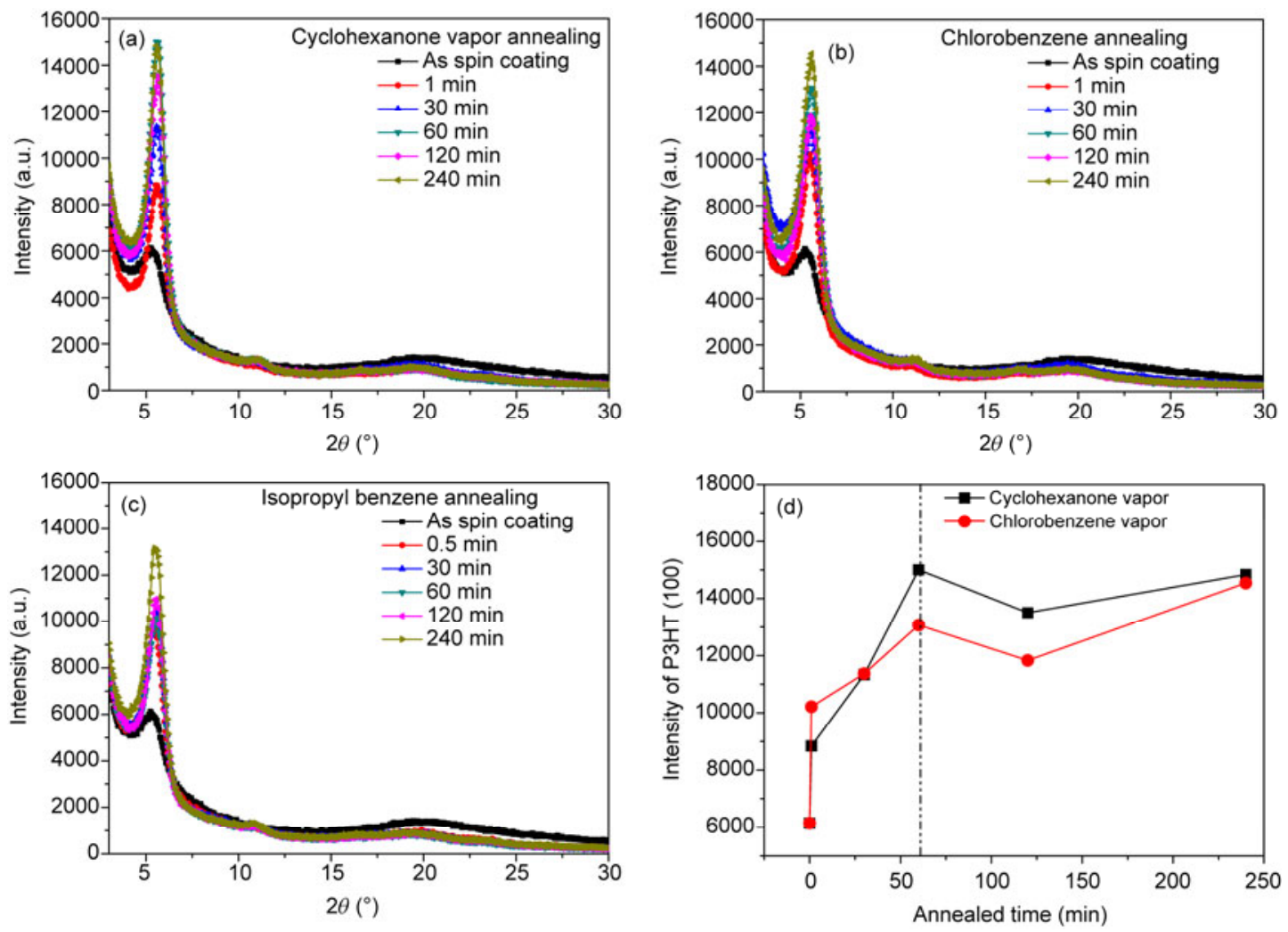

Figure 3 GIXD profiles for P3HT/ PCBM films annealed in (a) cyclohexanone, (b) chlorobezene and (c) isopropyl benzene vapor, respectively. (d) The intensity of P3HT (100) in GIXD profiles of the films annealed in different solvent vapors for different time.
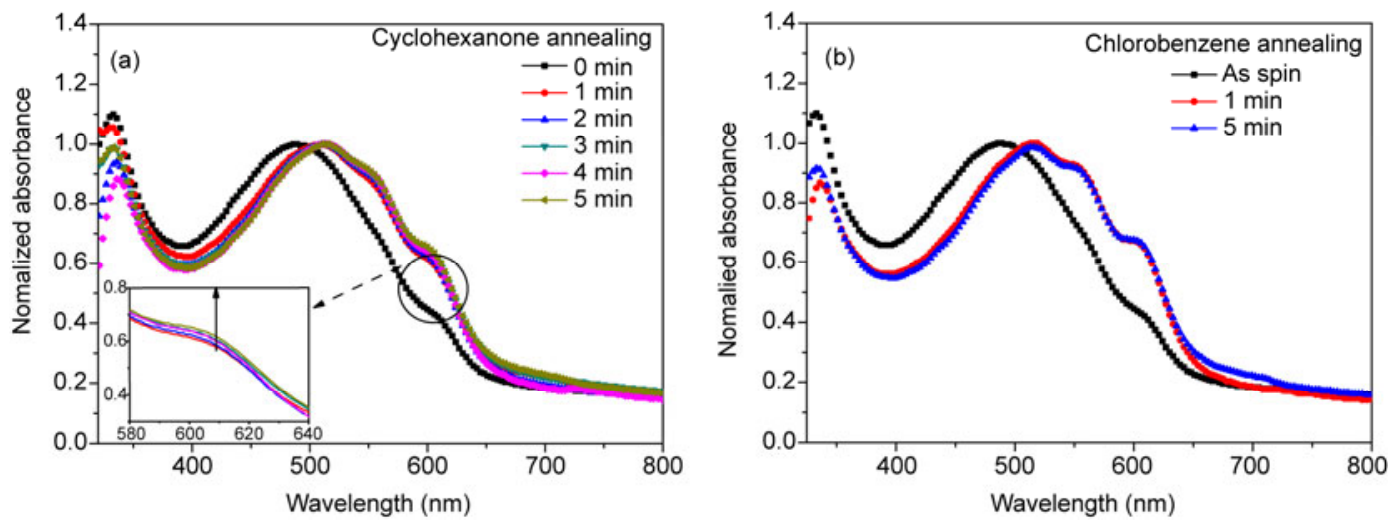

Figure 4 Absorption spectra for P3HT/PCBM films annealed for 1-5 min in (a) cyclohexanone and (b) chlorobezene vapor, respectively. The insets show the magnified images of the specific regions labeled by a dark circle.

while a selective solvent vapor not. It agrees with the conclusion deduced from the GIXD results that the crystallization of P3HT in films annealed in cyclohexanone vapor is slower.

\subsection{The role of solvent vapor in the morphology evolution of P3HT/PCBM blend films}

As mentioned above, a selective solvent vapor is preferred to induce PCBM to nucleate and aggregate, while a good solvent vapor is prefererred to induce self-organization of
P3HT. Cyclohexanone, isopropyl benzene and chlorobenzene have similar boiling point, that is, 155.6, 152 and $132^{\circ} \mathrm{C}$, respectively as shown in Table 1 . However, they have different solubility for the two constituents. Cyclohexanone and isopropyl benzene are selective solvents, which are good for PCBM but poor for P3HT. Chlorobenzene has a good solubility for both of them. The P3HT/PCBM films annealed in cyclohexanone and isopropyl benzene vapor present the similar morphologies, different from those in chlorobenzene. Therefore, we attribute the different evolution of P3HT/PCBM films in cyclohexanone and chlorobenzene 
vapor to the different solubility of the solvents.

When annealed in a selective solvent vapor, PCBM nucleates greatly and aggregates in a small size in the first few minutes. The size of PCBM aggregates keep unchanged until annealed for $60 \mathrm{~min}$ and larger PCBM aggregates of micron-size form hours later. On the contrary, the growth rate of PCBM aggregates is faster and PCBM their size is bigger when treated with a good solvent vapor. Meanwhile, the crystallinity of P3HT had nothing to do with the types of annealing solvents, although the rates of P3HT self-organization are different. Summarily, the morphology goes through three stages in a selective solvent vapor (Scheme 1): nucleation of PCBM, the slow increase of P3HT crystallinity and formation of larger-sized PCBM aggregates. In the first few minutes, lots of PCBM aggregates with a 10-20 nm scale appear while the crystallinity of P3HT is not improved greatly. It has been proved that a random polymer matrix can act as soft scaffolding where PCBM can only form nanoscale aggregates [19]. Because of a poor solubility for P3HT, the polymer chains move slowly and there are lots of disordered domains in the films. Therefore, in a selective solvent vapor, PCBM would nucleate fast and form aggregates with a small size. Then the polymer chains move slowly and the crystallinity of P3HT is enhanced. For the reason of the poor solubility for $\mathrm{P} 3 \mathrm{HT}$, the crystallization rate of P3HT is slow. There is not enough space for PCBM to aggregate further. Therefore, the size of PCBM aggregates keeps almost the same in this stage. Finally, after a few hours, larger PCBM aggregates of even micron-size begin to form when the crystallinity of P3HT is high enough. Beal et al. [27] showed that adjacent small-size PCBM aggregates could merge into one bigger aggregate. It might be the reason that micron-sized PCBM aggregations appeared suddenly in the third stage. But in a good solvent vapor, the self-organization of P3HT and the aggregation of PCBM are almost at the same time, which is difficult to control. In Figures 1 and 3 , it is found that when the crystallinity of $\mathrm{P} 3 \mathrm{HT}$ is high enough the PCBM aggregates of micro-size appear, too. It means that self-organization of P3HT is accompanied with the phase separation. It agrees with the previous literatures [14,21] which concluded that the crystallization of P3HT can promote phase separation.

\subsection{Photovoltaic devices}

Photovoltaic devices based on P3HT/PCBM blend films were fabricated according to standard ITO/PEDOT:PSS/ P3HT:PCBM/LiF/Al architecture. The current density-voltage $(I-V)$ curves of the devices annealed for 0-60 min in cyclohexanone or chlorobenzene vapor, were shown in Figure 5 and Table 3. The power conversion efficiency (PCE) of devices annealed in cyclohexanone vapor is higher than that in chlorobenzene vapor. In cyclohexanone vapor, the best device is attributed to the one annealed for $40 \mathrm{~min}$ (PCE was $2.64 \%$ ). While in chlorobenzene vapor the best one is attributed to the one annealed for 20 min (PCE was 2.35\%), which is earlier than the ones in cyclohexanone vapor. We attributed the different performance of devices annealed with different solvent vapor to the nanostructure of the films as discussed above. When the blend films are annealed for less than $30 \mathrm{~min}$, the crystallinity of P3HT increases with time and is higher in chlorobenzene vapor than that in cyclohexanone vapor. When the blend films are annealed for more than $30 \mathrm{~min}$, the crystallinity of P3HT has almost nothing to do with the type of solvent, but the degree of phase separation is different. The mean area of PCBM aggregates in films annealed by cyclohexanone vapor is much smaller than that in chlorobenzene vapor, as shown in Table 2.

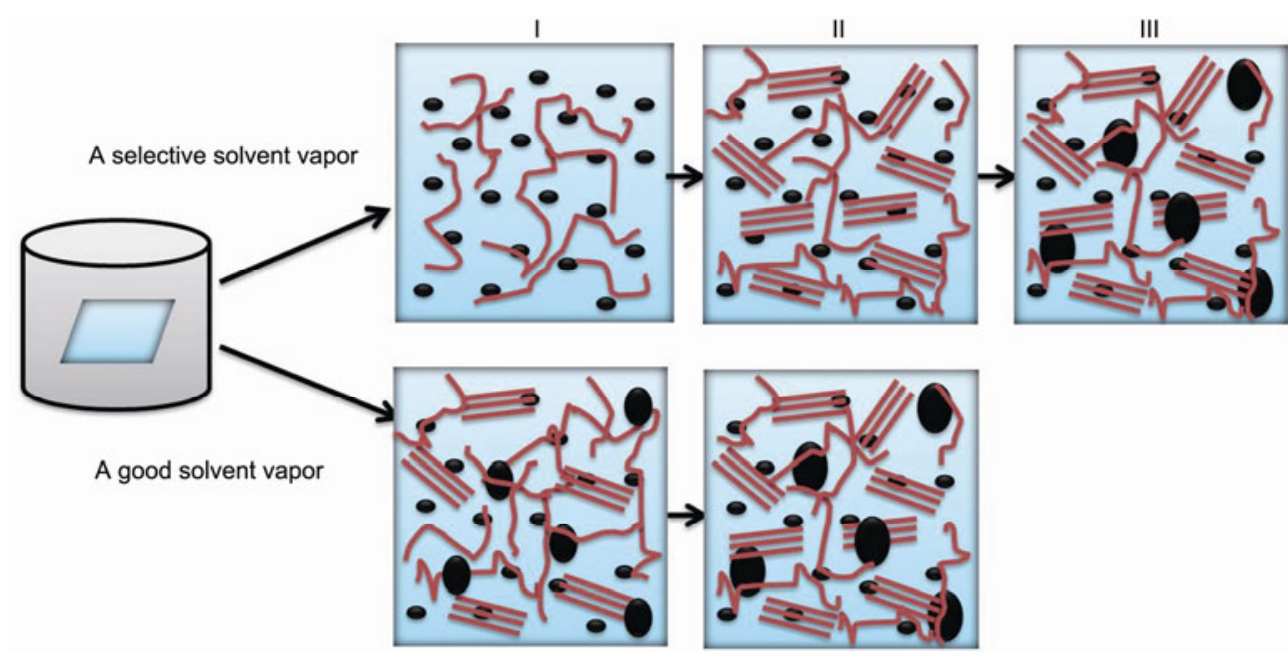

Scheme 1 The scheme illustration of the morphology evolution of P3HT/PCBM films annealed in different solvent vapors. The morphology undergoes three stages in a selective solvent vapor: (I) nucleation of PCBM with a small aggregate size occurs while the crystallinity of P3HT is low in the first few minutes, (II) the crystallinity of P3HT slowly increases while PCBM still has a small aggregate size before 60 min, (III) large-sized PCBM clusters form hours later. On the contrary, the self-organization of P3HT and the larger aggregation of PCBM take place almost at the same time when the films annealed for a few minutes in a good solvent vapor. 

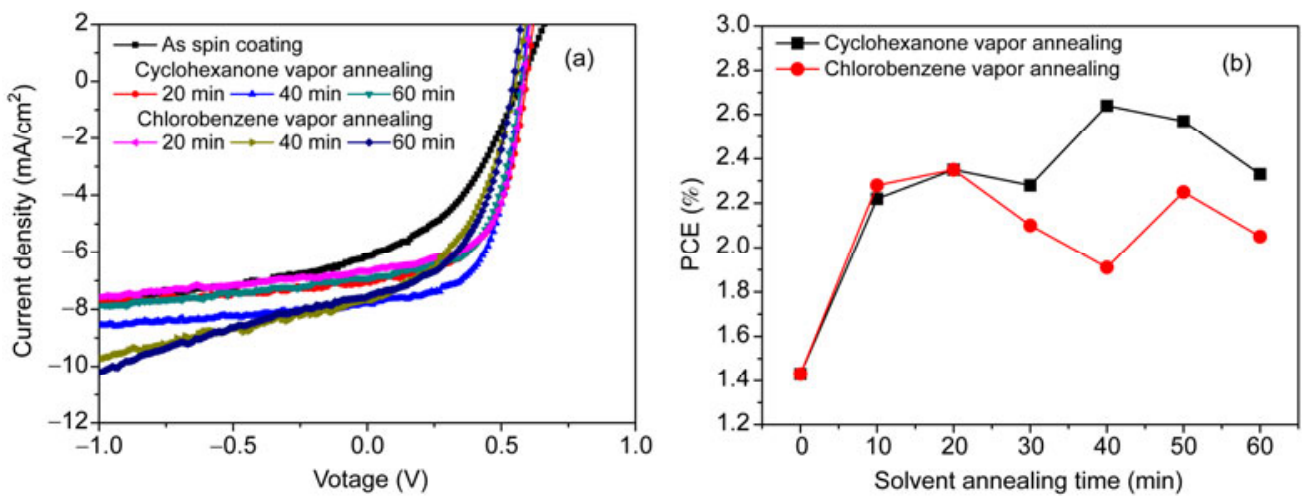

Figure $5 I-V$ curves for devices based on P3HT/PCBM films annealed in different solvents from 0 to 60 min. The $J_{\mathrm{sc}}, V_{\mathrm{oc}}, \mathrm{FF}$ and PCE were listed in Table 3.

Table 3 The $J_{\mathrm{sc}}, V_{\mathrm{oc}}$, FF and PCE obtained from Figure 5

\begin{tabular}{lcccc}
\hline & $V_{\mathrm{oc}}(\mathrm{V})$ & $J_{\mathrm{sc}}\left(\mathrm{mA} / \mathrm{cm}^{2}\right)$ & FF & PCE $(\%)$ \\
\hline As spin coating & 0.57 & 6.14 & 0.41 & 1.43 \\
Cyclohexanone 10 min & 0.57 & 7.17 & 0.54 & 2.22 \\
Cyclohexanone 20 min & 0.59 & 7.03 & 0.57 & 2.35 \\
Cyclohexanone 30 min & 0.59 & 7.10 & 0.55 & 2.29 \\
Cyclohexanone 40 min & 0.57 & 7.80 & 0.59 & 2.64 \\
Cyclohexanone 50 min & 0.57 & 7.46 & 0.60 & 2.57 \\
Cyclohexanone 60 min & 0.58 & 6.92 & 0.58 & 2.33 \\
Cyclohexanone 10 min & 0.62 & 6.27 & 0.59 & 2.28 \\
Chlorobenzene 20 min & 0.58 & 6.67 & 0.61 & 2.35 \\
Chlorobenzene 30 min & 0.56 & 7.75 & 0.48 & 2.10 \\
Chlorobenzene 40 min & 0.55 & 7.67 & 0.45 & 1.90 \\
Chlorobenzene 50 min & 0.58 & 6.87 & 0.56 & 2.25 \\
Chlorobenzene 60 min & 0.54 & 7.56 & 0.50 & 2.05 \\
\hline
\end{tabular}

This phase separation of a smaller size would reduce the recombination and decrease exciton loss [24]. Therefore, the highest PCE of devices in chlorobenzene vapor is the one annealed for $20 \mathrm{~min}$. The performance of devices in cyclohexanone vapor is higher than the ones in chlorobenzene vapor after annealed for more than $30 \mathrm{~min}$.

\section{Conclusions}

In conclusion, a selective solvent vapor, cyclohexanone or isopropyl benzene, which is poor for P3HT and good for PCBM, is employed to induce PCBM to aggregate first and decrease the rate of crystallization of P3HT. As a result, the size of PCBM aggregates is reduced and formation of big aggregates of PCBM is prolonged in P3HT/PCBM film. The morphology evolution undergoes three stages in a selective solvent vapor: (I) nucleation of PCBM with a small aggregate size and low crystallinity of $\mathrm{P} 3 \mathrm{HT}$ in the first few minutes, (II) the crystallinity of P3HT slowly increasing while PCBM still with a small aggregate size when annealed for less than $60 \mathrm{~min}$ and (III) large-sized PCBM clusters formation hours later. On the contrary, the selforganization of P3HT and the aggregation of PCBM take place almost at the same time in a few minutes when the films are annealed in a good solvent vapor. The difference is attributed to the different solubility of annealing solvent for P3HT. Because of the smaller size of phase separation, the device annealed in a selective solvent vapor for more than 30 min has a higher PCE than that annealed in a good solvent vapor.

This work was supported by the National Natural Science Foundation of China (51273191, 51073151), and the National Basic Research Program of China (2009CB930603, 2009CB623604).

1 Ma W, Yang C, Gong X, et al. Thermally stable, efficient polymer solar cell with nanoscale control of the interpenetrating network morphology. Adv Funct Mater, 2005, 15: 1617-1622

2 Li G, Shrotriya V, Huang J S, et al. High-efficiency solution processable polymer photovoltaic cells by self-organization of polymer blends. Nat Mater, 2005, 4: 864-868

3 Li Z, Zhao X, Lu X, et al. Organic thin-film solar cells: Devices and materials. Sci China Chem, 2012, 55: 553-578

4 Lee S S, Loo Y L. Structural complexities in the active layers of organic electronics. Annu Rev Chem Biomol Eng, 2010, 1: 59-78

5 Watkins P K, Walker A B, Verschoor G L B. Dynamical Monte Carlo modelling of organic solar cells: The dependence of internal quantum efficiency on morphology. Nano Lett, 2005, 5: 1814-1818

6 Maturová K, van Bavel S S, Wienk M M, et al. Description of the morphology dependent charge transport and performance of polymer: Fullerene bulk heterojunction solar cells. Adv Funct Mater, 2011, 21: 261-269

7 Erb T, Zhokhavets U, Gobsch G, et al. Correlation between structural and optical properties of composite polymer/fullerene films for organic solar cells. Adv Funct Mater, 2005, 15: 1193-1196

8 Lan Y K, Huang C I. Charge mobility and transport behavior in the ordered and disordered states of the regioregular Poly(3-hexylthiophene). J Phys Chem B, 2009, 113: 14555-14564

9 Sirringhaus H, Brown P J, Friend R H, et al. Two-dimensional charge transport in self-organized, high-mobility conjugated polymers. Nature, 1999, 401: 685-688

10 Kim K, Liu J, Namboothiry M A G, et al. Roles of donor and acceptor nanodomains in $6.1 \%$ efficient thermally annealed polymer photovoltaics. Appl Phys Lett, 2009, 90: 163511

11 Yang X, Loos J, Veenstra S C, et al. Nanoscale morphology of high-performance polymer solar cells. Nano Lett, 2005, 5: 579-583

12 Zhao Y, Xie Z, Qu Y, et al. Solvent-vapor treatment induced perfor- 
mance enhancement of poly(3-hexylthiophene): Methanofullerene bulk-heterojunction photovoltaic cells. Appl Phys Lett, 2007, 90: 043504

13 Miller S, Fanchini G, Lin Y Y, et al. Investigation of nanoscale morphological changes in organic photovoltaics during solvent vapor annealing. J Mater Chem, 2008, 18: 306-312

14 Bull T A, Pingree L S C, Jenekhe S A, et al. The role of mesoscopic PCBM crystallites in solvent vapor annealed copolymer solar cells, ACS Nano, 2009, 3: 627-636

15 Keawprajak A, Piyakulawat P, Klamchuen A, et al. Influence of crystallizable solvent on the morphology and performance of P3HT: PCBM bulk-heterojunction solar cells. Sol Energy Mater Sol Cells, 2010, 94: 531-536

16 Chan S H, Hsiao Y S, Hung L I, et al. Morphology evolution of spincoated films of poly(thiophene-phenylene-thiophene) and [6,6]-phenylC71-butyric acid methyl ester by solvent effect. Macromolecules, 2010, 43: 3399-3405

17 Yao Y, Hou J, Xu Z, et al. Effects of solvent mixtures on the nanoscale phase separation in polymer solar cells. Adv Funct Mater, 2008, 18: 1783-1789

18 Liu J, Shao S, Wang H, et al. The mechanisms for introduction of ndodecylthiol to modify the P3HT/PCBM morphology. Org Electron, 2010, 11: 775-783

19 Wang T, Pearson A J, Lidzey D G, et al. Evolution of structure, optoelectronic properties, and device performance of polythiophene: Fullerene solar cells during thermal annealing. Adv Funct Mater,
2011, 21: 1383-1390

20 Agostinelli T, Lilliu S, Labram J G, et al. Real-time investigation of crystallization and phase-segregation dynamics in P3HT:PCBM solar cells during thermal annealing. Adv Func Mater, 2011, 21: 17011708

21 Woo C H, Thompson B C, Kim B J, et al. The influence of poly (3-hexylthiophene) regioregularity on fullerene-composite solar cell performance. J Am Chem Soc, 2008, 130: 16324-16329

22 C-Quiles M, Kanai Y, El-Basaty A, et al. Ternary mixing: A simple method to tailor the morphology of organic solar cells. Org Electron, 2009, 10: 1120-1132

23 Treat N D, Brady M A, Smith G, et al. Interdiffusion of PCBM and P3HT reveals miscibility in a photovoltaically active blend. Adv Energy Mater, 2011, 1: 82-89

24 Park J H, Kim J S, Lee J H, et al. Effect of annealing solvent solubility on the performance of poly(3-hexylthiophene)/methanofullerene solar cells. J Phys Chem C, 2009, 113: 17579-17584

25 Jo J, Kim S S, Na S I, et al. Time-dependent morphology evolution by annealing processes on polymer: Fullerene blend solar cells. Adv Funct Mater, 2009, 19: 866-874

26 Tang H, Lu G, Li L, et al. Precise construction of PCBM aggregates for polymer solar cells via multi-step controlled solvent vapor annealing. J Mater Chem, 2010, 20: 683-688

27 Beal R M, Stavrinadis A, Warner J H, et al. The molecular structure of polymer-fullerene composite solar cells and its influence on device performance. Macromolecules, 2010, 43: 2343-2348

Open Access This article is distributed under the terms of the Creative Commons Attribution License which permits any use, distribution, and reproduction in any medium, provided the original author(s) and source are credited. 